University of Nebraska - Lincoln

DigitalCommons@University of Nebraska - Lincoln

Mammalogy Papers: University of Nebraska

State Museum

Museum, University of Nebraska State

December 2007

\title{
Using scissors to quantify hardness of insects: Do bats select for size or hardness?
}

\author{
Patricia W. Freeman \\ University of Nebraska-Lincoln, pfreeman1@unl.edu \\ Cliff A. Lemen \\ University of Nebraska-Lincoln, clemen2@unl.edu
}

Follow this and additional works at: https://digitalcommons.unl.edu/museummammalogy

Part of the Zoology Commons

\footnotetext{
Freeman, Patricia W. and Lemen, Cliff A., "Using scissors to quantify hardness of insects: Do bats select for size or hardness?" (2007). Mammalogy Papers: University of Nebraska State Museum. 39. https://digitalcommons.unl.edu/museummammalogy/39

This Article is brought to you for free and open access by the Museum, University of Nebraska State at DigitalCommons@University of Nebraska - Lincoln. It has been accepted for inclusion in Mammalogy Papers: University of Nebraska State Museum by an authorized administrator of DigitalCommons@University of Nebraska Lincoln.
} 


\title{
Using scissors to quantify hardness of insects: Do bats select for size or hardness?
}

\author{
P. W. Freeman \& C. A. Lemen \\ School of Natural Resources and University of Nebraska State Museum \\ University of Nebraska-Lincoln, Lincoln, NE, USA
}

\begin{abstract}
Scissors are used to determine the hardness of fresh insects of different size and taxa. Our results indicate a strong relationship between the size of an insect and its hardness, which can be expressed as $\log \left(F_{\max }\right)=0.65 \times \log (V)+\alpha . F_{\max }$ is the maximal force needed to cut the insect and is our measure of insect hardness. $V$ is the volume of the insect and a is a constant that can be derived for different insect taxa. The value of 0.65 was found as an average of beetle and moth samples, and this number appears consistent across insect taxa. We found that beetles averaged about 3.2 times harder than moths of the same size. Beetles were also more variable in hardness than moths, with the softest beetles about equal in hardness to an average moth of the same size. Using our data on insect hardness coupled with data on the diets of bats and their bite forces from the literature, we attempt to determine whether the upper size limit of insects taken by a bat is limited by the insect's dimensions or its hardness. Our results indicate that both these factors may be important.
\end{abstract}

Keywords: cutting, insect size, insect hardness, bat prey, prey selection, size selection, beetle-eating bats, moth-eating bats, jaw mechanics, biomaterials.

Correspondence: Patricia W. Freeman, School of Natural Resources and University of Nebraska State Museum, University of Nebraska-Lincoln, Lincoln, NE 68588-0514, USA. Email: pfreeman1@unl.edu

\section{Introduction}

Several authors have hypothesized a relationship between the jaw and tooth morphology of bats and the hardness of the food they consume. Freeman $(1979,1981)$ suggested that bats consuming harder insects (beetles) have larger teeth and heavier, shorter jaws than those specialized on a diet of softer insects (moths). The possibility of such a correlation has created interest in the quantification of the hardness of prey items and in attempting more rigorous tests. One approach used to quantify the hardness of insects has been to categorize families or orders of insects as having characteristic hardness based on the researcher's general knowledge of insects with no direct measurement of insect hardness (Freeman, 1981; Carraway et al., 1996). Hence beetles were given a hardness of 5 while moths received a hardness of 2 in Freeman (1981). Less subjectively, insect hardness has also been quantified in the laboratory (Strait \& Vincent, 1998; Aguirre et al., 2003; Evans \& Sanson, 2005). Their basic methods involve measuring the force or work necessary to part or penetrate an insect. Strait \& Vincent (1998) quantified the work needed to cut through an insect's abdomen with scissors. Aguirre et al. (2003) and Evans \& Sanson (2005) used flat-end punches and measured the force needed to penetrate the insects. Both methods have advantages; here we use the scissors method to quantify both measures of what might broadly be called toughness and hardness of insects. Unfortunately, both toughness and hardness have definitions within material sciences that may make the use of the terms problematic. Evans \& Sanson (2005) felt this problem was significant enough to use the term "intractability." We sympathize with their dissatisfaction with these terms, but do not feel that intractability is an improvement. In this paper we continue to use the terms hardness or softness to describe insects. Specifically, our definition of an insect's hardness is the largest force needed to part the insect using a sharp scissors $\left(F_{\max }\right)$.

The first problem we faced is determining what quantities need to be measured that will be related to the biological problems faced by a bat chewing an insect. One classic representation of toughness is the area under the stress strain curve for a standard size sample of a material (Willems, Easley \& Rolfe, 1981). Thus, toughness is the amount of work needed to sever a specimen of known cross-sectional area. We agree with Vincent (1990) that such traditional methods of quantifying toughness fail when dealing with complex biological structures such as whole insects. Thus, we followed the solution proposed by Atkins \& Mai (1979) and subsequently adapted by Lucas \& Pereira (1990), Vincent (1992) and Strait \& Vincent (1998). The biological specimen (in our case an insect) is cut with a scissors and the input work applied to the scissors is a measure of the work of fracture $\left(W_{\mathrm{f}}\right)$. Then a measure of the toughness of the insect, $T$, was found by dividing $W_{\mathrm{f}}$ by the cross-sectional area of the cut created by the scissors in the specimen. Division by cross-sectional 
area is designed to standardize the work to the area of the cut (because insects cannot be milled to a standard size as a steel bar might be). In the ideal experiment to determine $T$ and $W_{\mathrm{f}}$, all the work applied to the scissors goes to extending the fracture. In reality, work is also expended on plastic and elastic deformation of material as well as friction between the scissors and the insect. Atkins \& Mai (1979) have expressed the need to avoid or compensate for these problems to derive the true toughness of the material. Indeed, the logic behind the use of the guillotine and scissors approach is to concentrate work at the point of fracture. Atkins \& Mai (1979) did a careful analysis to control for these problems, but their approach was largely made possible by the homogeneous and sheet-like form of the specimens they cut. Strait \& Vincent (1998) acknowledged these problems, but maintained that the use of scissors would help concentrate work at the point of fracture. While this is undoubtedly true, it is difficult for us to equate the toughness of a metal foil as determined by Atkins \& Mai (1979) and the toughness of a beetle, which is a very complex bundle of material. The potential for some of the work being "wasted" in plastic or elastic deformation, friction and fractures created other than at the scissors' edges is significant. Fortunately for our study, it may not matter. The insectivore must pierce and chew the intact insect; therefore, what we are measuring with scissors is probably biologically relevant. Because of the inherent difficulty of measuring the true work of fracture, we take the area under our force-deflection curve to be the work of parting, $W_{\mathrm{p}}$, and the toughness index derived from $W_{\mathrm{p}}$ as $T_{\mathrm{p}}$ (Figure 1).

Our measure of hardness is the maximum force needed to part the insect, $F_{\max }$. Although we have measured and will report $T_{\mathrm{p}}, W$ and $F_{\text {max }}$, we have a preference for the biological significance of $F_{\text {max }}$. Although toughness has been used by Strait \& Vincent (1998) as an important measure of a dietary item, it suffers from the fact that it is a material property and not a structural property of the food item. For example, a sheet of aluminum foil that is $0.025 \mathrm{~mm}$ thick can be cut easily with a pair of scissors. The same alloy of aluminum in a 10 -mm-thick plate could not be cut by hand with scissors. The material property of the aluminum is the same but the outcome is different. For this reason we prefer the biological relevance of $F_{\max }$ in this study. The second comparison, between the biological relevance of $W_{\mathrm{p}}$ and $F_{\text {max }}$, is subtler. $F_{\max }$ is a measure of the maximum bite force needed to part an insect whereas $W_{\mathrm{p}}$ is a measure of the work needed to part an insect. $F_{\max }$ relates directly to maximum bite force that has been studied as an important factor for a predator to handle prey (Meers, 2002, and references therein). We prefer $F_{\text {max }}$ as the critical factor to measure in prey. Fortunately, as discussed below, there is a high correlation between $F_{\max }$ and $W_{\mathrm{p}}$ in our study $\left(R^{2}=0.90\right)$. However, if food items under study were to range from very brittle to very tough material (such as glass and leather), then the distinction between $F_{\max }$ and $W_{\mathrm{p}}$ might have to be made.

The emphasis on $F_{\text {max }}$ is consistent with the approach of Aguirre et al. (2003) and Evans \& Sanson (2005), who used flat-ended punches to test for the hardness of insect cuticle.
They concluded that the maximal force needed to send a standard punch through the insect cuticle was the best measure of hardness. Evans \& Sanson (2005) felt this measure was superior to the work done during puncture and specific puncture force and specific work (found by dividing force or work by cuticle thickness). We agree with their conclusion of the importance of maximum force $\left(F_{\max }\right)$ as the most relevant measure and, although our method using a scissors to cut whole insects is different from their method using a punch on isolated cuticle, our conclusions about the relevant measures of hardness are similar.

The second part of our study will be to apply our findings to test two hypotheses about what limits the upper size of insects taken by bats. Our first hypothesis is that the upper limit of insect prey taken is based on the insect's physical dimensions. The idea is that, given the jaw length of a bat, it can handle rapidly insects up to a certain size only. Our second hypothesis is that bats are limited by the strength of their jaws and the hardness of prey (Aguirre et al., 2003). Testing these hypotheses is somewhat confounded because large insects, on average, are harder than small insects. However, a greater knowledge of insect hardness and the strength of bat jaws will allow additional conclusions to be drawn.

\section{Materials and methods}

We collected 78 insect species in the summer of 2004 in the state of Nebraska (USA). The insects were predominantly coleopterans ( 29 species) or lepidopterans (21 species) mostly caught at night with a light trap. Insects were included in the study on the basis of availability and not by known inclusion in a bat's diet. Each specimen was measured for length, width and height. The specimens were mounted on a plastic slotted stage with polyacrylic glue and cut with new Joewell Cobalt5000 , straight, hair-cutting scissors mounted on an Instron InSpec 2200 testing machine (Instron Corporation, MA, USA)

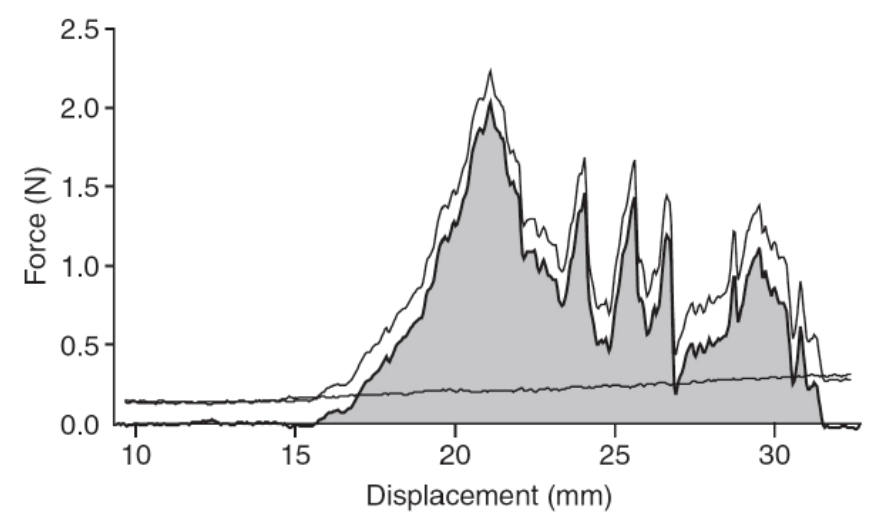

Figure 1. Relationship between displacement of scissors and forces for the control run (no insect present; thin, slightly inclined line just above the $x$-axis), raw data for cutting a $12 \mathrm{~mm}$ pentatomid (topmost curve), and force data corrected by subtraction of control data (bold curve). Area under the bold curve is shaded and represents $W_{p}$. 
with a 500N load cell (see Strait \& Vincent, 1998 for illustration of the method). The jig for the scissors was made of wood so that the plastic platform with the insect could be attached to the lower blade and still allow the scissors to close.

Using scissors we determined the total work needed to cut an insect longitudinally and head-on along its mid-line. This method follows the approach using scissors employed by Strait \& Vincent (1998) and Lucas \& Pereira (1990). To find $W_{\mathrm{p}}$ we subtracted the work needed to close the scissors without an insect (a control run) from the work needed to cut the insect. This process can be seen graphically in Figure 1. The highest curve is the displacement-force curve obtained while cutting the insect (a $12 \mathrm{~mm}$ pentatomid). The lowest curve is the displacement-force curve for a control run. The bold line is the difference between the curve for cutting the insect and the control run. $W_{\mathrm{p}}$ is the area under this last curve (area in gray in Figure 1). Following Vincent (1990), we quantified an index of toughness $\left(T_{\mathrm{p}}\right)$ by dividing $W_{\mathrm{p}}$ by the cross-sectional area of the insect (length $\times$ height).

Calculation of $F_{\text {max }}$ is more complex because this force must be calculated at the insect and is not the force needed to close the scissors, which is being measured directly by the Instron machine. This is not a trivial problem because not only is the mechanical advantage altered as the length of the output arm increases as the scissors close, but also the angle of attack (approach angle) of the blade also changes (Atkins \& Mai, 1979). To convert the force data from the Instron machine to the actual force delivered on the specimen, we needed a conversion function. We derived this function experimentally by cutting a piece of $0.09 \mathrm{~mm}$ white copy paper ( $20 \mathrm{lb}$ stock). Not surprisingly, the input force increases as the blade closes and the mechanical advantage of the scissors is decreased (Figure 2a). We fitted a fifth degree polynomial, g, to this relationship between force and displacement (also plotted in Figure 2a). Through measurement of input arm and output arm at zero displacement (initial open position of the scissors), we know that the scissors had an initial mechanical advantage of 4.7. We then calculated a correction factor at displacement $d$ as $\mathrm{CF}_{d}=4.7(g(0) / g(d))$, where $g(0)$ is the value of the polynomial at 0 displacement and $g(d)$ is the value of the polynomial at displacement $d$. This correction factor is then multiplied to the corresponding force value from the Instron data to obtain the corrected force. Figure $2 \mathrm{~b}$ plots the corrected forces for the copier paper. Figure $2 \mathrm{c}$ plots the data for cutting the rutelin beetle Anomala flavipennis; $F_{\max }$ is then found to be the maximal corrected force needed along the cut, in this case about $1.2 \mathrm{~N}$.

Bite forces were found by using the regression published by Aguirre et al. (2002). The weights of bats needed for this equation were taken from published values for each species. The dentary lengths for bats were taken from museum specimens for most species (Freeman, 1998). Where species were not available, dentary length was estimated using a regression of body weight to dentary length for a large, representative sample of microchiropteran bats [dentary length $=$ 5.46 $\left(\right.$ weight $\left.\left.^{1 / 3}\right)+0.129 ; R^{2}=0.88\right]$.
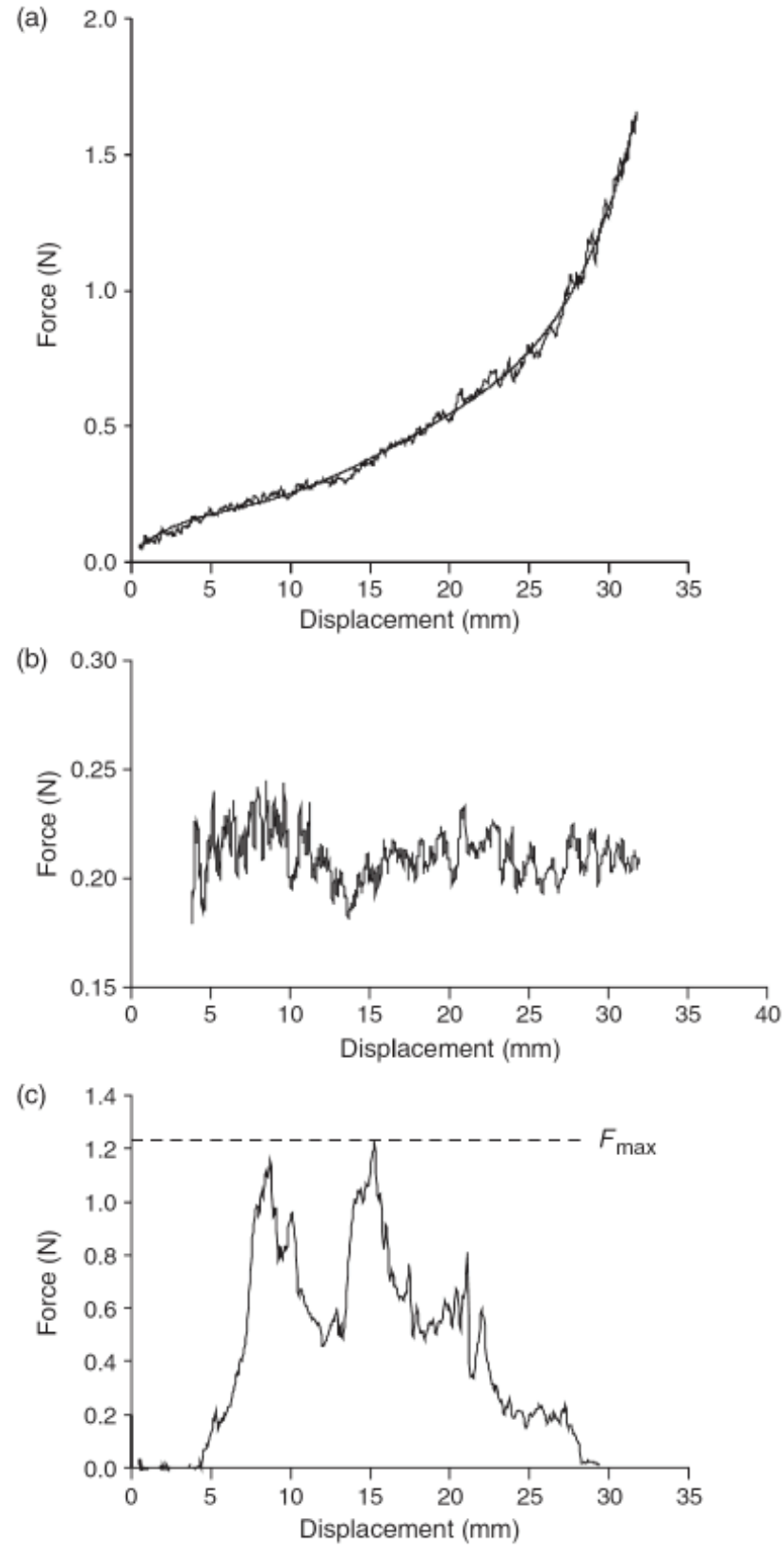

Figure 2. Graphical representation of the method of calculating $F_{\text {max }}$. (a) Raw force to input displacement on the scissors for a cut through paper. Also plotted is the fifth degree polynomial fitted to this curve. (b) Force to displacement data after adjustment by the polynomial of part (a). For our scissors the average force to cut this paper is about $0.21 \mathrm{~N}$. (c) Adjusted data from cutting the beetle Anomala flavipennis. $F_{\text {max }}$ for these data is about $1.2 \mathrm{~N}$.

The lengths of largest beetles and moths eaten by different species of bats were taken from the literature (Acharya \& Fenton, 1992: Lasiurus cinereus and Lasiurus borealis; Eckrich \& Neuweiler, 1988: Hipposideros lankadiva; Hooper \& Brown, 1968: Noctilio labialis (= albiventris); Jacobs, 1996: L. cinereus; O'Neill \& Taylor, 1989: Chalinolobus morio, Nyctophilus timoriensis, Vespadelus regulus, Vespadelus sagittula, Vespadelus vulturnus, and Falsistrellus tasmaniensis; 
Pavey \& Burwell, 1997: Hipposideros diadema; Pine, 1969: Molossus ater; Pine \& Anderson, 1979: Trachops cirrhosus; Ross, 1967: Euderma maculatum, Myotis velifer, Plecotus townsendii, Idionycteris phyllotis; Vaughan, 1977: Hipposideros commersoni). The quality of the data varied greatly. The best data sets were the large studies by O'Neil \& Taylor (1989) and Acharya \& Fenton (1992). These data were analyzed separately before grouping all the data together.

\section{Results}

A summary of our results can be seen in Figure 3 with the graphs of $T_{\mathrm{p}}, W_{\mathrm{p}}$ and $F_{\max }$ versus size of insect. Note that in Figure $3 \mathrm{c}$ there is a clear difference in the toughness of moths and beetles. The mean toughness for beetles is 0.40 and that for moths is only 0.098 (analysis of covariance showed a significant effect of groups $F=36, P<0.001$ ). Also note that $T_{\mathrm{p}}$ increases with volume of the insect so that large insects are tougher than small insects (also a significant relationship in the analysis of covariance $F=82, P<0.001$ ). In other words, the work to cut an insect does not scale to the cross-sectional area of the cut but closer to the volume of the insect. This can be seen in the exponential regression of work to volume for moths $\left(\right.$ work $=3.8 \times$ volume $\left.^{0.94}\right)$. Beetles and moths do have overlap in $T_{\mathrm{p}}$ even when the size effects are removed.

$W_{\mathrm{p}}$ and $F_{\text {max }}$ are highly correlated $\left(R^{2}=0.90\right)$ in our insects. Neither $W_{\mathrm{p}}$ nor $F_{\max }$ has been scaled for size as $T_{\mathrm{p}}$ has by division by the fracture cross-sectional area, and there is a strong influence of both taxon and size in these log-transformed data (Figure 3a and b). An analysis of covariance of $F_{\max }$ for the beetle and moth data indicates that there are highly significant effects of both insect volume $(F=204$, d.f. $=1,75, P<0.001$ ) and taxon (beetle vs. moth; $F=83$, d.f. $=1,75, P<0.001)$. Analysis shows a significant difference in intercept $(P<0.05)$ but not in slope $(P>0.5)$ between moths and beetles. The difference in intercept indicates that beetles have an average $F_{\text {max }} 3.16$ times greater than the average moth of similar size. In other words, the average moth would have to be 2.5 times the length of an average beetle to have the same $F_{\max }$. The relationship between force and volume can be expressed as $\log \left(F_{\max }\right)=\beta \log ($ volume $)+\alpha$. The equation is $\log \left(F_{\max }\right)=0.645 \log ($ volume $) \times 4.06$ for moths and $\log \left(F_{\max }\right)=0.654 \log ($ volume $) \times 2.91$ for beetles.

Aguirre et al. (2003) found a slope of 1.91 between the $\log$ of force of penetration and the log of insect length for beetles. Using insect length we found a slope of $1.83(\mathrm{SE}=0.18)$ with $F_{\text {max }}$. In our analysis the slope for $F_{\text {max }}$ was similar for moths (2.07). Unfortunately, Aguirre et al. (2003) did not report the slope for moths; hence no comparison can be made.

Although samples from other orders of insects are smaller, several interesting patterns emerge (Figure 4). The first is that moths are not easier to part than insects from many other groups. Diptera, Neuroptera, Odonata, Orthoptera, Plecoptera and Trichoptera have about the same $F_{\text {max }}$ whereas Ephemeroptera have lower hardness. Like beetles, Hemiptera and Ho- moptera have a wide range of $F_{\max }$, making them intermediate between moths and beetles. The two hymenopterans that we cut both had high $F_{\text {max }}$ for their body volumes; indeed, the highest positive residual from the beetle regression line was for the velvet ant (Mutillidae). Given the small sample sizes in these groups, it is hard to refine our conclusions.
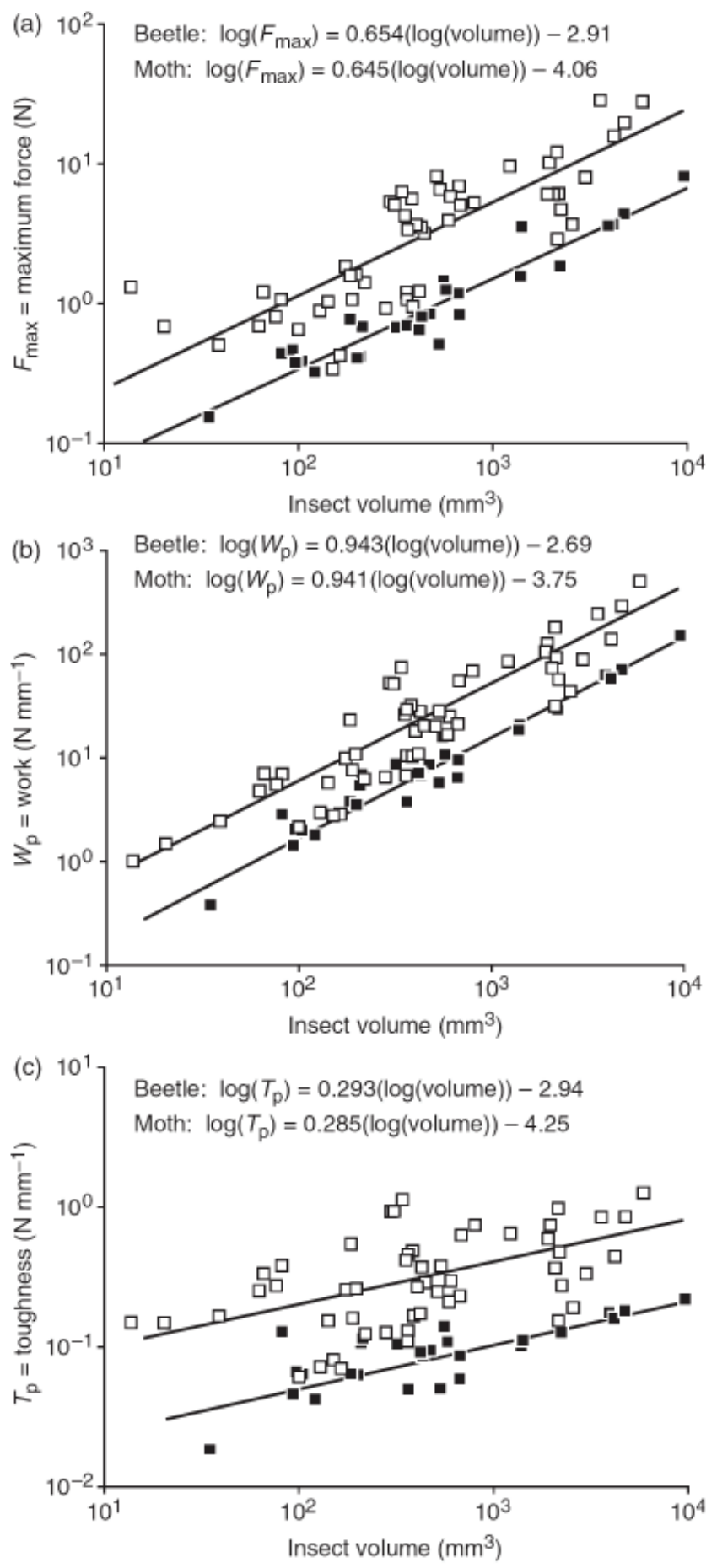

Figure 3. Relationship between $F_{\max }$ and insect volume (a), work and insect volume (b) and toughness and insect volume (c) for beetles ( $\square$ ) and moths ( $\mathbf{\square})$. Also shown are regression lines from an analysis of covariance. In general, beetles are harder and tougher than moths and take more work to cut or part. 
On average, larger bats take larger insects (solid squares in Figure 5a, $\left.R^{2}=0.72, P<0.001\right)$. Also, larger bats have longer dentaries (open squares in Figure 5a, $R^{2}=0.88, P<$ $0.001)$. However, the slopes of these two regressions are different. Larger bats take relatively large insects relative to their jaw length. A subtler pattern can be found when comparing the size of beetles and moths in diets (Figure 6). Analysis of covariance of cube root of bat weight versus insect length for our best data sets shows a significant effect of both bat weight $(F=37, P<0.001)$ and insect taxon $(F=6, P<0.05)$. The difference in intercepts of the moth and beetle lines indicates that, for a given size, these bats ate moths that were about 1.3 times larger than the beetles in their diets. However, when we extended our analysis to all diet studies, the relationship was no longer significant. This may be a problem with the quality of data in some of the studies. Results from O'Neil \& Taylor (1989) and Acharya \& Fenton (1992) are the best available for our comparison of moths and beetles taken by bats. O'Neil \& Taylor (1989) found that significantly larger moths were taken by five of six species of bats in their study.

Figure $5 \mathrm{~b}$ plots a series of points based on diet data from bats. Each point represents a species of bat where $F_{\max }$ calculated from the largest beetle or moth in its diet is plotted against the bat's mass ( $F_{\max }$ calculated using average values for moths and beetles based on our regressions). Also plotted is a line showing the relationship between body weight and bite force derived by Aguirre et al. (2002). Two different relationships are plotted against the bat's mass: first is the relationship between the $F_{\max }$ of the largest insects taken by a bat and second, the maximal force that can be generated by the

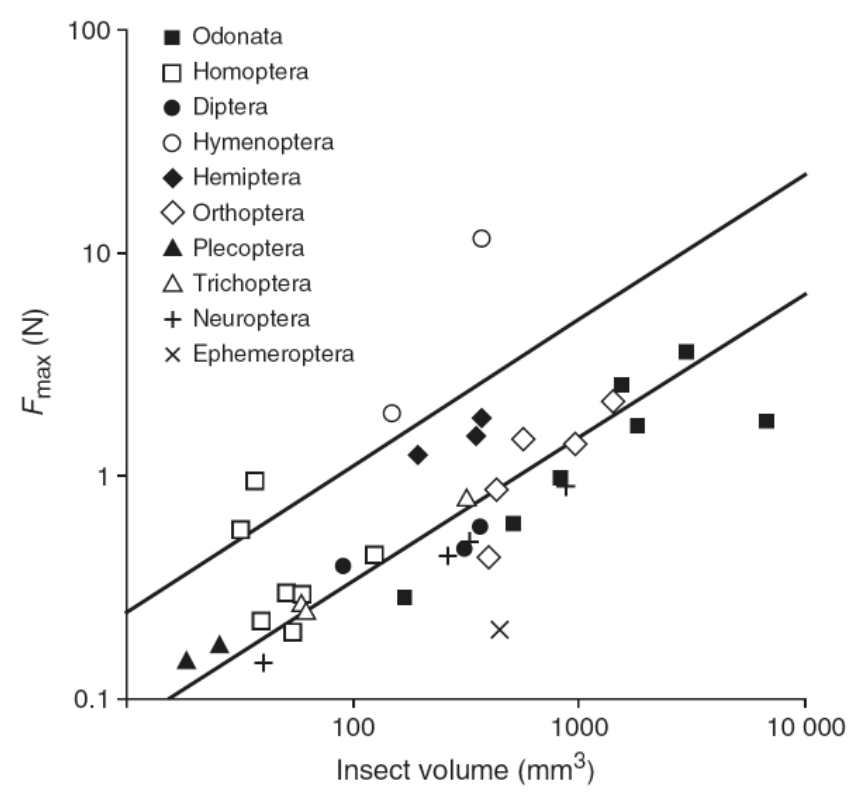

Figure 4. Relationship between $F_{\max }$ and insect volume for the remaining insects in our study. Regression lines for beetle data (upper line) and moth data from Figure $3 a$ are plotted for comparison.

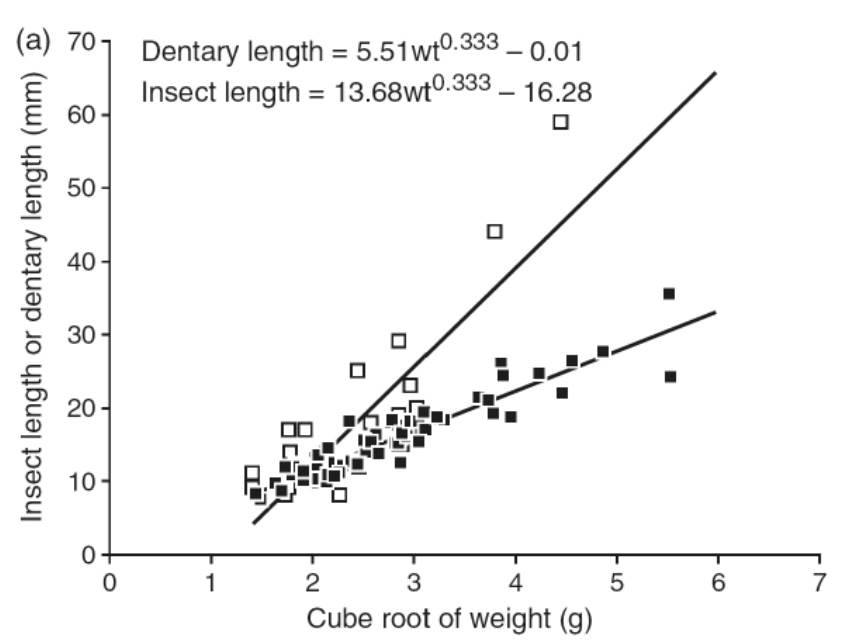

(b)

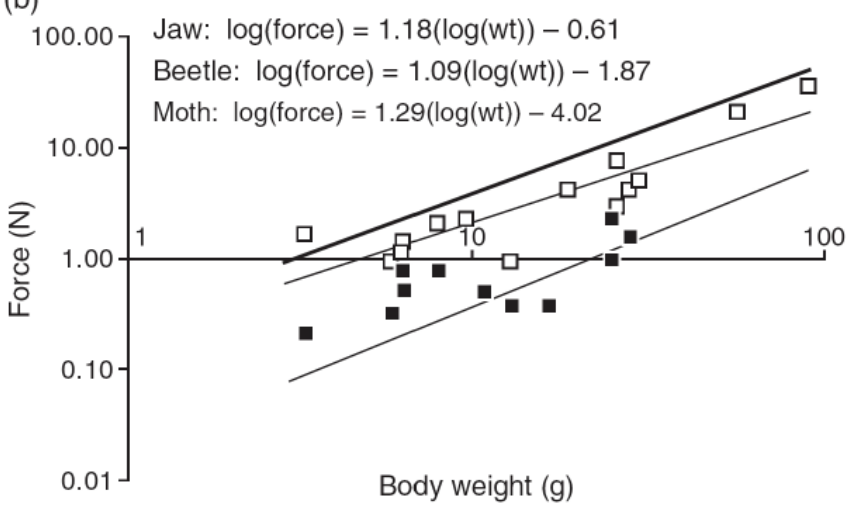

Figure 5. (a) Solid squares show the relationship between dentary length and the cube root of bat weight. Open squares show the relationship between the maximum length of moths and beetles eaten by a bat and the cube root of bat weight. These slopes are dissimilar. (b) Relationship between $F_{\max }$ for beetles ( $\square$ ) and moths ( $\square$ ) plotted against bat weight. The top line is the regression found between a bat's weight and the maximal bite force its jaws can generate and closely parallels the beetle and moth regression lines.

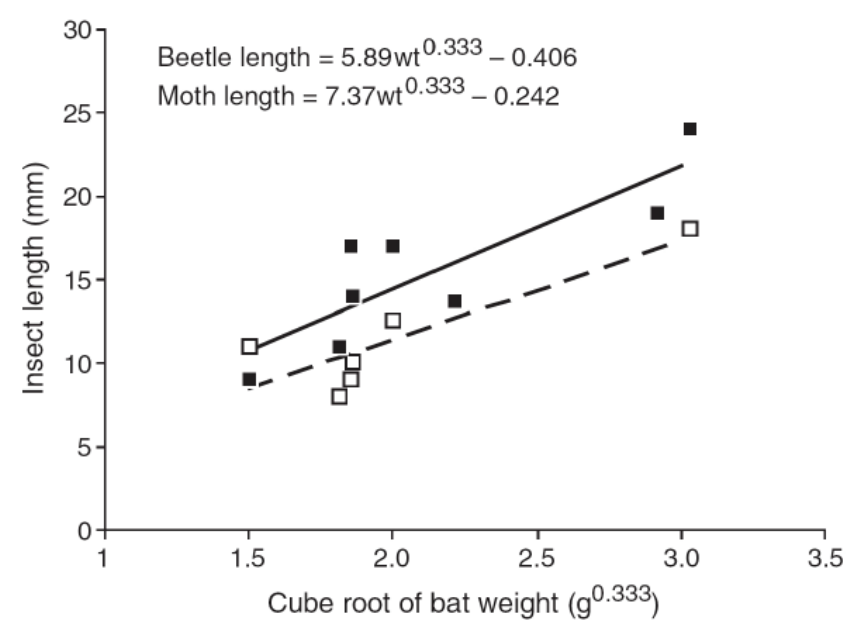

Figure 6. Relationship between bat weight and length of beetles ( $\square$ ) and moths ( $\square)$ taken from the best dietary data available. On average, bats eat larger moths than beetles. 


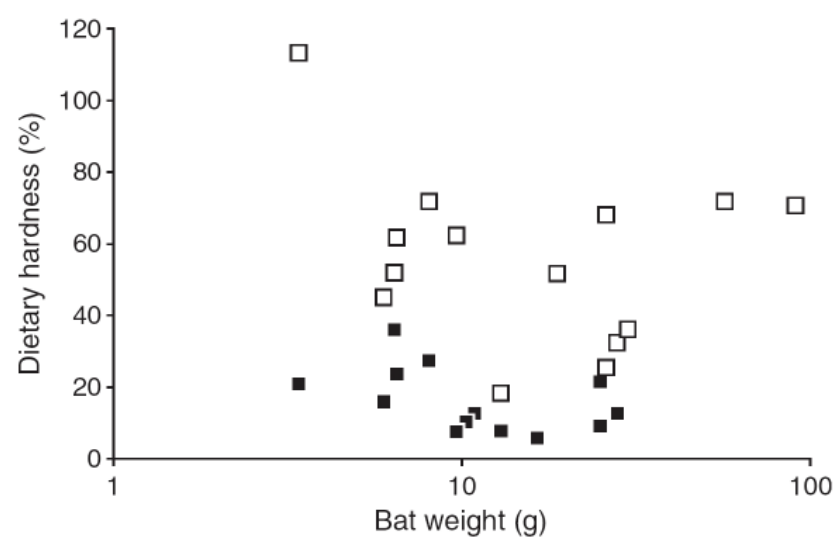

Figure 7. Relative dietary hardness of largest beetles ( $\square$ ) and moths (घ) taken by a bat plotted against the bat's weight. There is no significant relationship between relative dietary hardness and bat weight; however, moths are significantly softer dietary items than beetles.

bat's jaws. Thus Figure $5 \mathrm{~b}$ is analogous to Figure $5 \mathrm{a}$ where we found that changes in jaw length with increasing body size did not parallel changes in the length of insects included in the bat's diet. In Figure $5 b$ however changes in bite force closely parallel changes in the $F_{\max }$ values.

A percentage index of relative dietary hardness for an insect in a bat's diet can be found by dividing the insect's $F_{\text {max }}$ by the bat's bite force. Thus, as $F_{\text {max }}$ approaches bite force this index approaches $100 \%$. Analyzing beetles and moths separately, we found that there is no significant relationship between a bat's weight and this relative index of dietary hardness (Figure 7). Thus, larger bats do not take relatively harder or softer prey than small bats. There is a significant difference in this relative dietary hardness between the beetles and moths taken $(F=25, P<0.01)$, indicating that on average beetles in a bat's diet are harder than moths.

\section{Discussion}

Our analysis indicates that $F_{\max }$ is affected by both insect size and taxon. Beetles have higher average $F_{\max }$ than moths of the same size, but a large moth will have a higher $F_{\text {max }}$ than a small beetle. The slope of the regression line between insect volume and $F_{\max }$ is fairly consistent across taxa at about 0.65. The differences in groups of insects is in the elevation of the line. Although moths may be thought of as soft bodied, several other groups of insects have similar relationships between body volume and $F_{\max }$. Beetles are considered hard bodied, but this group showed more variability around the regression line than moths. Soft-bodied beetles have values of $F_{\text {max }}$ similar to a moth of the same size. Given the strong relationship between $F_{\max }$ and size within both moths and beetles, size must be considered in any discussion of insect hardness. However, in bat diets, the size range of insects eaten is often relatively narrow (O'Neill \& Taylor, 1989), and our analysis indicates that the moths eaten by bats typically represent relatively soft portions of their diet as compared to the beetles consumed (Figure 7). Ultimately this confirms Freeman's $(1979,1981)$ notion that moth eaters eat relatively soft prey. Given the sizes of prey actually consumed, the largest moths taken by bats have relative dietary hardness that averages about $16 \%$. This index for the largest beetles in a bat's diet averages about $58 \%$.

Larger bats tend to eat larger insects. There are several reasons why bats restrict the upper size of the insect they take. One hypothesis is that, as aerial insectivores, bats can most efficiently handle prey up to a certain size because of the physical dimensions of the insect. If the insect is too large, it will not fit in the bat's mouth and may slow down processing. Some bats that take large insects land to manipulate and eat their prey, but many bats consume the insect while still on the wing. Thus, if the insect is too long, some sort of oral juggling would have to be done to chew it. At some point the extra time involved may not be compensated by the additional calories in the larger insect. Another hypothesis is that the size of the largest insect taken is determined by the insect's hardness (Aguirre et al., 2003). It may not be an absolute impossibility to chew the larger insects, but harder insects could take longer to chew and a bat's time might be better spent pursuing smaller prey. Thus, these two hypotheses concentrate on the importance of two different aspects of an insect's size: linear dimensions and $F_{\max }$.

If the hardness hypothesis is correct, length does not matter and bats should eat larger moths than beetles. We found that for a moth to have the same $F_{\text {max }}$ as an average beetle, it would have to be 2.5 times longer. Several bats that eat both beetles and moths have been found to eat larger moths than beetles, but the size ratio is only 1.3 and not the predicted 2.5 . One consequence of this is that the beetles they eat are harder to chew than the moths (Figure 7).

If the handling hypothesis is correct, one would predict that prey size increases with bat size as a function of gape or jaw size. If the hardness hypothesis is correct, one would predict that prey size is determined by the relationship between bite force and the insect's $F_{\max }$. Using dentary length as an index of jaw size, we found that small bats eat insects approximately as long as their dentaries. However, as bats get larger, insect size increases much faster than dentary length (Figure 5a). The prediction of the hardness hypothesis, that $F_{\max }$ of the largest insects in a bat's diet should increase in tandem with the bat's bite force, is confirmed (Figure $5 b$ ).

Thus, our investigation of these hypotheses has produced conflicting results. On the one hand, the similarity of slope in bite force and $F_{\max }$ supports the hardness hypothesis, as does the fact that some studies show that bats take larger moths than beetles. However, if only hardness were important, bats should be willing to eat much larger moths than beetles, and this does not appear to happen. Several possibilities exist to explain this pattern; for instance, does hardness limit the 
size of beetles taken, but dimensions are limiting in the softer moths? This issue will require further investigation.

An interesting corollary arises from the insect hardness versus length problem. If a bat specializes on eating beetles that are relatively large for its jaw forces, there should be selection for short powerful jaws. Longer jaws might allow easier manipulation of larger prey, but the loss of mechanical advantage might overrule this alteration. On the other hand, bats that eat relatively large moths may face less of a problem with prey hardness and be able to lengthen jaws to ease manipulation of prey. Therefore, species that specialize in eating relatively large beetles should be short jawed and have large jaw muscles. Species that eat relatively large moths should have relatively long jaws and have relatively less need for powerful muscles.

Are bats near their maximum bite force with the hardest beetles in their diet? With estimates of bite force and insect hardness, can we combine this information to predict whether a bat can chew up a particular insect? Aguirre et al. (2003) tried to arrive at this, but we feel there is a problem in their attempt to equate their maximal force using a punch with maximal bite force. We see no way to convert the flat-end punch or scissors results to the resistance encountered as a bat chews an insect. Comparison of our data with those of Aguirre et al. (2003) shows that their forces averaged 2.3 times higher than ours (but importantly the slopes of force to insect length are similar). Our scissors, being razor sharp, would represent a minimum $F_{\max }$, but this force cannot be equated to what is encountered by the bat. It is only a relative index of hardness. For example, Aguirre et al. (2003) used a flat-end punch that had an end surface area of $3.0 \mathrm{~mm}^{2}$. However, it would not be surprising that insects are easier to penetrate with a smaller punch. Thus, we can create a relative measure of the resistance the bat will find in chewing up an insect but not the absolute value its jaws will encounter. This line of reasoning puts our measure of relative dietary hardness in perspective. A $100 \%$ value would be relative to our scissors-derived $F_{\max }$ and not a measure of the maximal force needed by the bat's teeth to part the insect.

On the basis of our use of scissors as well as the work of others, we can draw some conclusions about estimating the hardness of whole insects (see Evans \& Sanson, 2005 for an alternative approach using cuticle thickness). Firstly, for ease of use and repeatability between studies, the flat-end punch has clear advantages. No corrections have to be made for mechanical advantage as with scissors. The punch can be reproduced by other researchers with a minimum of effort. With scissors, the exact same model of scissors would have to be used with the same sharpness of blades. On the other hand, we found scissors especially effective at measuring cutting forces in very delicate insects. With a punch there can be a confusing smashing of the insect without a clear point of penetration. However, to allow some comparison among scissor studies, we suggest that a control test on standard stock copier paper be reported. This will allow a conversion factor to be created to compare results among studies.

\section{Acknowledgements}

Our thanks to Matt Paulsen, who collected and identified most of the insects; Marsh Lemen, master at capturing dragonflies; Ted Weiss, owner of State Beauty Supply, for helping us purchase professional hair-cutting shears; Angie Fox, museum technical artist, who put the figures in their final form; the School of Natural Resources, particularly Mark Kuzila, for funding; and the University of Nebraska State Museum for support. This is ARD research project \# 15247.

\section{References}

Acharya, L. \& Fenton, M. B. (1992). Echolocation behaviour of vespertilionid bats (Lasiurus cinereus and Lasiurus borealis) attacking airborne targets including arctiid moths. Can. J. Zool. 70, 1292-1298.

Aguirre, L. F., Herrel, A., Van Damme, R. \& Matthysen, E. (2002). Ecomorphological analysis of trophic niche partitioning in a tropical savannah bat community. Proc. Roy. Soc. Biol. Sci. Ser. B 269, 1271-1278.

Aguirre, L. F., Herrel, A., Van Damme, R. \& Matthysen, E. (2003). The implications of food hardness for diet in bats. Funct. Ecol. 17, 201-212.

Atkins, A. G. \& Mai, Y. W. (1979). On the guillotining of materials. J. Mater. Sci. 14, 2747-2754.

Carraway, L. N., Verts, B. J., Jones, M. L. \& Whitaker, J. O. Jr. (1996). A search for age-related changes in bite force and diet in shrews. Am. Midl. Nat. 135, 231-240.

Eckrich, M. \& Neuweiler, G. (1988). Food habits of the sympatric insectivorous bats, Rhinolophus rouxi and Hipposideros lankadiva from Sri Lanka. J. Zool. (Lond.) 215, 729-737.

Evans, A. R. \& Sanson, G. D. (2005). Biomechanical properties of insects in relation to insectivory: cuticle thickness as an indicator of insect 'hardness' and 'intractability'. Aust. J. Zool. 53, 9-19.

Freeman, P. W. (1979). Specialized insectivory: beetle-eating and moth-eating bats. J. Mammal. 60, 467-479.

Freeman, P. W. (1981). Correspondence of food habits and morphology in insectivorous bats. J. Mammal. 62, 154-159.

Freeman, P. W. (1998). Form, function, and evolution in skulls and teeth of bats. In Bat biology and conservation: 140156. Kunz, T. H. \& Racey, P. A. (Eds.). Washington and London: Smithsonian Institution Press.

Hooper, E. T. \& Brown, J. H. (1968). Foraging and breeding in two sympatric species of neotropical bats, genus Noctilio. J. Mammal. 49, 310-312.

Jacobs, D. S. (1996). Morphological divergence in an insular bat, Lasiurus cinereus semotus. Funct. Ecol. 10, 622-630. 
Lucas, P. W. \& Pereira, B. (1990). Estimation of the fracture toughness of leaves. Funct. Ecol. 4, 819-822.

Meers, M. B. (2002). Maximal bite force and prey size of $T y$ rannosaurus rex and their relationships to the inference of feeding behavior. Hist. Biol. 16, 1-12.

O’Neill, M. G. \& Taylor, R. J. (1989). Feeding ecology of Tasmanian bat assemblages. Aust. J. Ecol. 14, 19-31.

Pavey, C. R. \& Burwell, C. J. (1997). The diet of the diadem leaf-nosed bat Hipposideros diadema: confirmation of a morphologically-based prediction of carnivory. J. Zool. (Lond.) 243, 295-303.

Pine, R. H. (1969). Stomach contents of a free-tailed bat, Molossus ater. J. Mammal. 50, 162.

Pine, R. H. \& Anderson, J. E. (1979). Notes on stomach contents in Trachops cirrhosus (Chiroptera: Phyllostomatidae). Mammalia 43, 568-570.
Ross, A. (1967). Ecological aspects of the food habits of insectivorous bats. Proc. West. Found. Vert. Zool. 1, 205-264.

Strait, S. G. \& Vincent, J. F. V. (1998). Primate faunivores: physical properties of prey items. Int. J. Primatol. 19, 867-878.

Vaughan, T. A. (1977). Foraging behaviour of the giant leafnosed bat (Hipposideros commersoni). E. Afr. Wildl. J. 15, 237-249.

Vincent, J. F. V. (1990). Fracture properties of plants. $A d v$. Botan. Res. 17, 235-287.

Vincent, J. F. V. (1992). Fracture. In Biomechanics - materials, a practical approach: 193-218. Vincent, J. F. V. (Ed.). Oxford: IRL Press at the University Press.

Willems, N., Easley, J. T. \& Rolfe, S. T. (1981). Strength of materials. New York, NY: McGraw-Hill Book Company. 